
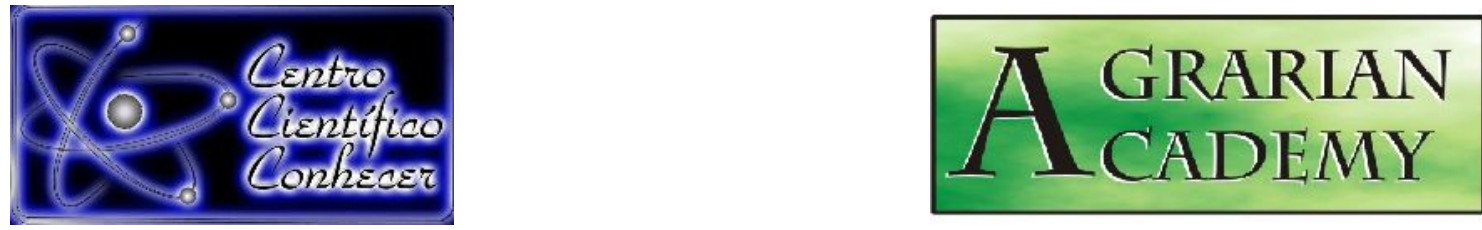

\title{
ECOFISIOLOGIA DE ÁRVORES EM UM ANO DE SECA NA TRANSIÇÃO CERRADO-AMAZÔNIA
}

\author{
Charles Caioni
}

Doutor em Ecologia e Conservação pela Universidade Estado de Mato Grosso, Alta

Floresta-MT, Brasil, (charlescaioni@gmail.com)

Recebido em: 01/04/2020 - Aprovado em: 10/06/2020 - Publicado em: 30/07/2020

DOI: 10.18677/Agrarian_Academy_2020a9

\begin{abstract}
RESUMO
Seca severa estão ocorrendo com maior frequência na transição CerradoAmazônia, ao mesmo tempo que, pouco se sabe sobre seus efeitos na vegetação local. Assim, esta pesquisa teve como objetivo estudar a condutância estomática e a temperatura da superfície da folha das espécies Eugenia dysenterica e Virola sebifera, sob condições acentuadas de déficit hídrico. A coleta ocorreu entre 7:30 e 15:00 horas de 15/08/2015. Inicialmente foi registrada a temperatura do ar e a velocidade do vento a partir de anemômetros digitais. Posteriormente, foi registrada a temperatura da superfície da folha e a radiação fotossinteticamente ativa a partir de Porometrôs modelo SC-1 e Piranômetros ML01, respectivamente. Por último, obteve-se a condutância estomática com uma câmara de pressão de Scholander. Para a aquisição da condutância estomática e da temperatura da superfície da folha foram selecionadas para cada indivíduo três folhas maduras orientadas no sentido do sol (este procedimento foi repetido três vezes para cada indivíduo). Todas as análises foram feitas nos programas $\mathrm{R}$ (pacote Ime4). Eugenia dysenterica e Virola sebifera não demonstraram diferença significativa para a condutância estomática. A condutância estomática variou ao longo do dia em ambas as espécies, com máximas registradas entre 9:30 e 10:30 horas. A condutância estomática esteve baixa entre $11: 30$ a 12:30 horas, possivelmente em decorrência do aumento da temperatura foliar. De modo geral, constou-se que sob condições de elevado déficit hídrico, ambas a espécies tendem a aumentar a temperatura foliar e a reduzir a condutância estomática, a fim de reduzir a perda excessiva de água para a atmosfera.
\end{abstract}

PALAVRAS-CHAVE: Condutância estomática, Extremo climático, Sudeste Amazônico. 


\title{
TREE ECOPHYSIOLOGY IN A DRY YEAR IN THE CERRADO-AMAZON TRANSITION
}

\begin{abstract}
Severe drought are occurring more frequently in the Cerrado-Amazon transition, while little is known about its effects on local vegetation. Thus, this research aimed to study the stomatal conductance and the leaf surface temperature of the species Eugenia dysenterica and Virola sebifera, under severe water deficit conditions. The collection took place between 7:30 and 15:00 hours of 08/15/2015. Initially, air temperature and wind speed were recorded using digital anemometers. Subsequently, the leaf surface temperature and the photosynthetically active radiation were recorded from Porometrô model SC-1 and Piranómetro ML01, respectively. Finally, stomatal conductance was obtained with a Scholander pressure chamber. For the acquisition of stomatal conductance and leaf surface temperature, three mature leaves oriented towards the sun were selected for each individual (this procedure was repeated three times for each individual). All analyzes were performed using the $\mathrm{R}$ programs (Ime4 package). Eugenia dysenterica and Virola sebifera showed no significant difference for stomatal conductance. Stomatal conductance varied throughout the day in both species, with maximum recorded between 9:30 and 10:30 hours. Stomatal conductance was low between 11:30 am and 12:30 pm, possibly due to the increase in leaf temperature. In general, it was found that under conditions of high water deficit, both species tend to increase leaf temperature and reduce stomatal conductance, in order to reduce the excessive loss of water to the atmosphere.
\end{abstract}

KEYWORDS: Southeast Amazon, extreme climatic stomatal conductance.

\section{INTRODUÇÃO}

As florestas da transição Cerrado-Amazônia por meio de seus processos biogeoquímicos desempenham importantes papeis na regulação do clima local e regional (SANTOS, 2017; COPERTINO et al., 2019;). Isto porque, a floresta captura vapor d'água oriundo do oceano Atlântico que é precipitado sobre a floresta e depois retorna em grande parte para a atmosfera via evapotranspiração (REIS; OLIVEIRA, 2017). A floresta contribui ainda para o tamponamento da seca, mantendo elevada evapotranspiração e baixa temperatura da superfície e albedo, mesmo sob condições de elevado déficit hídrico (CAIONI et al., 2017; JANUARIO et al., 2017; ROTHMUND et al., 2019; CAIONI et al., 2020).

Embora a floresta influencie o clima, este também pode influenciar o funcionamento e a estrutura da floresta. Em anos de seca severa é esperado que espécies menos adaptadas venham a morrer em virtude da redução de água no solo e ao aumento da demanda de água para a atmosfera (NOBRE et al., 2016). Este cenário é preocupante, visto que projeções indicam que secas severas, como por exemplo, as de 2005, 2010 e 2015, irão tornar-se ainda mais frequentes no sudeste Amazônico, (SCHLESINGER et al., 2016; MARENGO et al., 2016; CAMPOS; SANTOS, 2017; SANTOS et al., 2018), região esta que abriga não apenas espécies Amazônicas, mas também do Cerrado.

É esperado que as árvores nativas presentes em manchas de cerrado no sul da Amazônia consigam suportar períodos mais prolongados de déficit hídrico, quando comparado a espécies Amazônicas. Isso porque, essas árvores possuem raízes profundas que permitem acessar água em diferentes profundidades do solo 
(BRAGA et al., 2017; MORAIS et al., 2017). Outro fato que contribui para uma maior resistência é a capacidade dessas árvores de reduzirem a área foliar nos meses de maior déficit hídrico (CARNEIRO et al., 2019).

Apesar dessas árvores possuírem diferentes estratégias adaptativas, ainda não há um consenso a respeito de como (de Cerrado) irão se comportar diante de eventos extremos de seca que poderão ocorrer no futuro. Nessa perspectiva, objetivou-se estudar a condutância estomática e a temperatura da superfície da folha das espécies Eugenia dysenterica e Virola sebifera, sob condições acentuadas de déficit hídrico.

\section{Área de estudo}

\section{MATERIAL E MÉTODOS}

O estudo foi conduzido em um fragmento de Cerradão presente dentro de uma área de transição Cerrado-Amazônia, situada no município de Gaúcha do

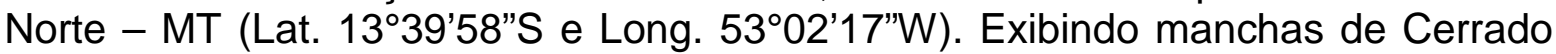
ao longo de seu território, a vegetação local é característica da transição CerradoAmazônia. O clima da região é tropical de monções (Am), com uma nítida estação seca e outra chuvosa (ALVARES et al., 2013; CURTO et al., 2018; CASAVECCHIA et al., 2019). A precipitação fica entorno dos $2000 \mathrm{~mm}$ ao ano.

\section{Procedimentos metodológicos}

O presente trabalho foi desenvolvido no final do mês de agosto (de 2015), visto que o mesmo consiste no período de maior intensidade da seca na região. Inicialmente foram selecionadas duas espécies nativas como objeto de estudo (Eugenia dysenterica, Virola sebifera). Posteriormente, entre as 7:30 e 15:00 horas do dia 15 de agosto foi obtida a condutância estomática foliar e a radiação fotossinteticamente ativa por meio de um porometrô modelo SC-1 e um Piranômetro ML01, respectivamente. Foi registrada ainda, a temperatura e velocidade do vento com um anemômetro digital. A condutância estomática foi obtida a partir de uma câmara de pressão de Scholander (1965). Descartando folhas consideradas muito jovens ou velhas foi mensurado (de cada indivíduo) três folhas maduras orientadas no sentido do sol. Este procedimento foi repetido três vezes para cada indivíduo.

As análises dos dados foram realizadas com o pacote Ime4 do programa $\mathrm{R}$ versão 3.0.2. Modelos lineares de efeitos mistos foram conduzidos para avaliar a diferença na condutância estomática de cada espécie. Foram realizadas ainda, regressões polinomiais entre os valores de temperatura foliar e radiação fotossinteticamente ativa.

\section{RESULTADOS E DISCUSSÃO}

As espécies Eugenia dysenterica e Virola sebifera não apresentaram diferença significativa quanto a condutância estomática $\left(r^{2}=0,12 ; p=0,7\right)$. Entretanto, a condutância estomática na espécie Eugenia dysenterica foi maior, demonstrando ser a espécie de maior capacidade de incorporação de biomassa em curto espaço de tempo.

Ao longo de todo o dia ambas espécies exibiram maior condutância estomática entre 9:30 e 10:30 horas. Isso porque a condutância estomática tende a ser maior quando a radiação solar é alta e o potencial hídrico ainda não alcançou valores mínimos capazes de induzir o fechamento estomático (RODRIGUES et al., 
2018). Para ambas espécies, foi observada menor condutância estomática entre 14:30 e 15:00 horas, devido ao aumento da temperatura foliar induzir ao fechamento estomático (BERTOLLI et al., 2015). As plantas adotam esta estratégia a fim de evitar que o potencial hídrico da folha desça a níveis abaixo dos considerados críticos para a estabilidade do sistema de transporte de água (OREN et al., 1999; FURQUIM et al., 2018). De modo geral a variação da condutância estomática ao longo do dia pode também estar relacionada a redução do potencial hídrico da folha, visto que ambos agem como um mecanismo de retroalimentação ou feedback.

FIGURA 1. Comportamento diurno da condutância estomática para Eugenia dysenterica (painel A) e Virola sebifera (painel B).
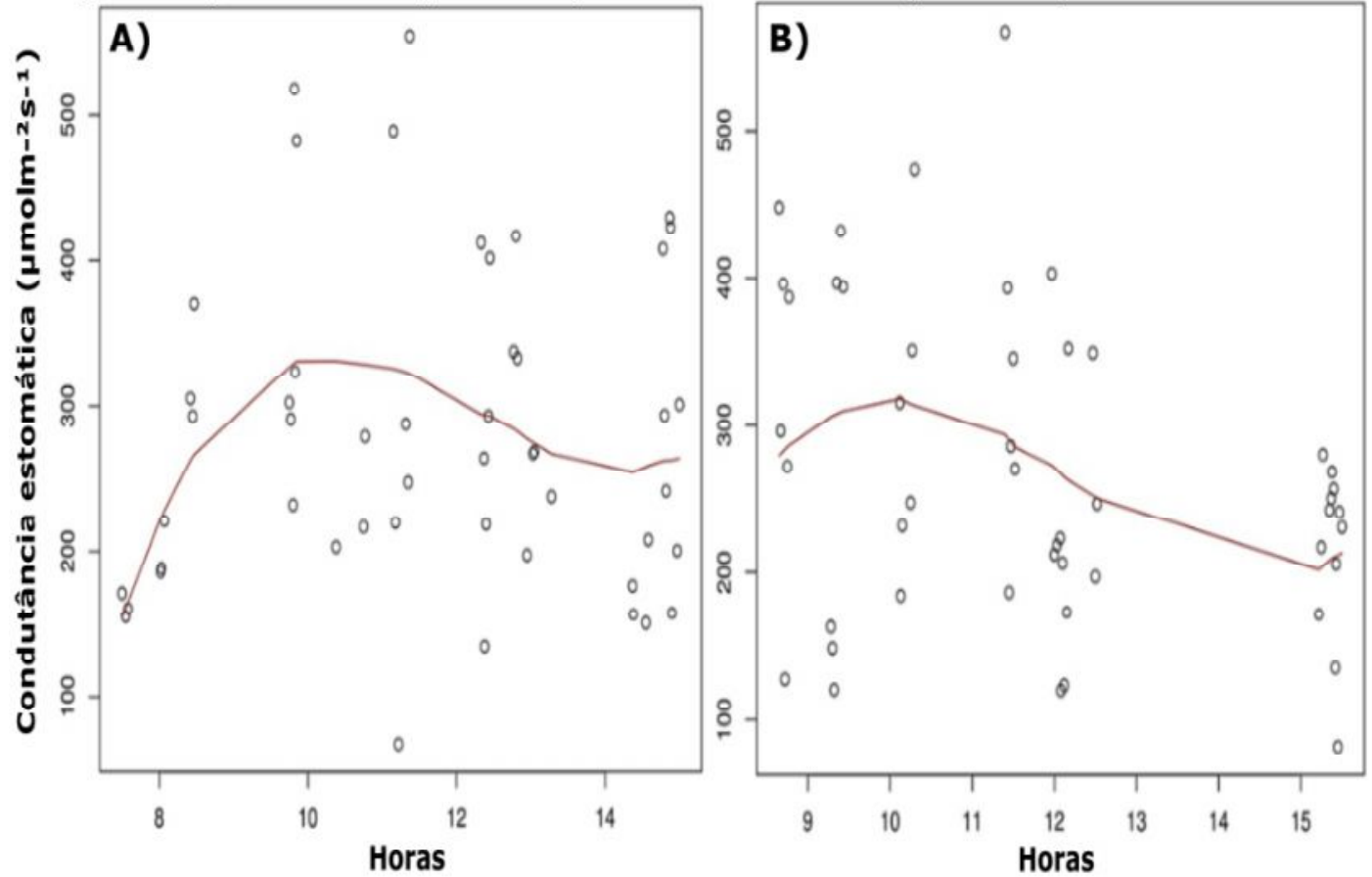

Fonte: próprio autor.

Ao longo do período estudado a temperatura média do ar ficou próxima aos $36,2^{\circ} \mathrm{C}$ (Figura 2). Esta temperatura está relacionada ao Cerradão possuir dossel mais aberto comparado aos de Florestas Ombrófila Aberta ou Densa. Estudos revelam ainda que, as folhas e ramos presentes na vegetação reduzem a quantidade da radiação solar que atinge os estratos inferiores da floresta, e por isso são observadas maiores temperaturas em ambientes mais abertos (SILVA; JARDIN, 2017; NOVAIS et al., 2018). 
FIGURA 2. Temperatura do ar (painel A) e velocidade do vento (painel B) entre 7:30 e 16:00 horas.

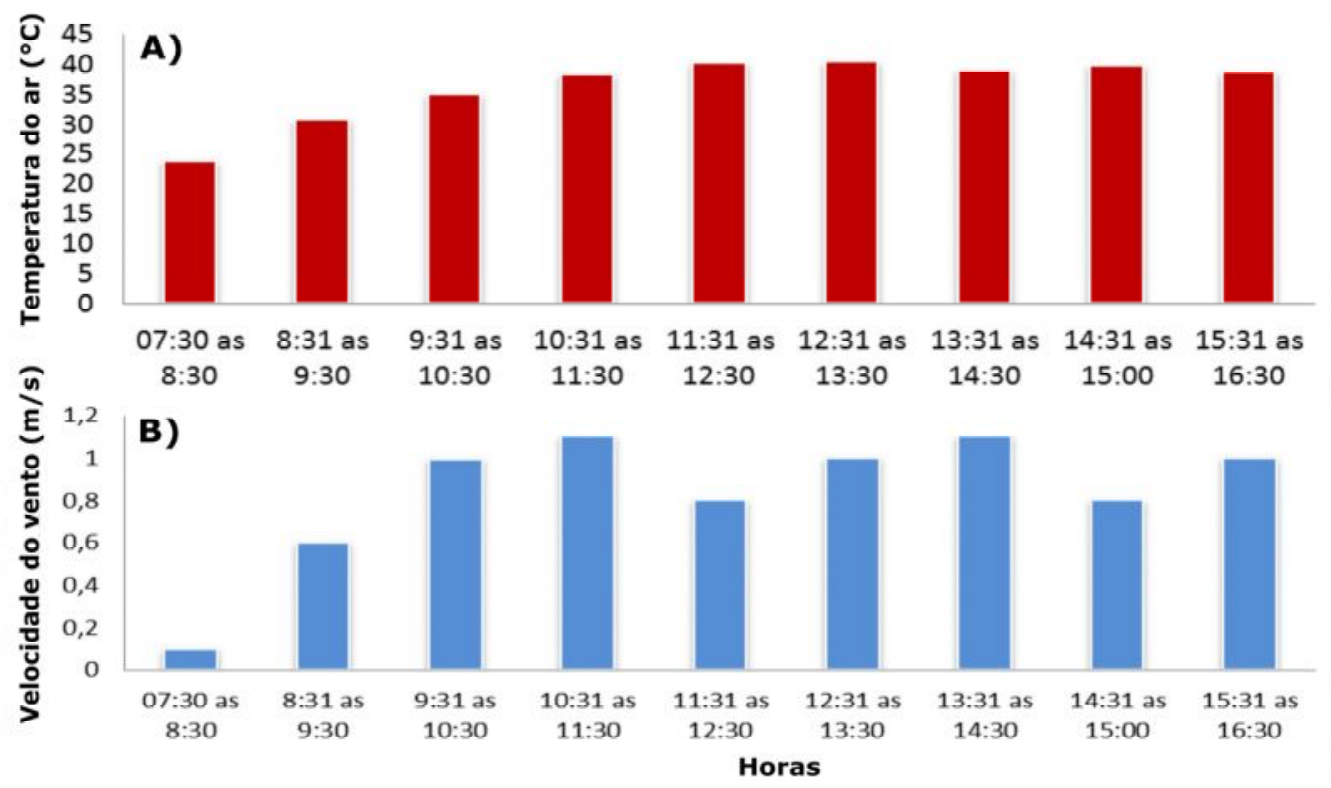

Fonte: próprio autor.

Com máximas e mínimas de 0 e 3,1 $\mathrm{m} / \mathrm{s}$ respectivamente, a área apresentou uma velocidade do vento média de $0,8 \mathrm{~m} / \mathrm{s}$. Estes valores estão relacionados a estrutura vertical da vegetação que permite maior passagem de corrente de ar. A movimentação dos ventos pode interferir nas taxas de condutância estomática e de potencial hídrico, visto que a passagem de correntes de ar reduz a quantidade de vapor de água presente na folha.

A radiação fotossinteticamente ativa (RFA) apresentou considerável oscilação ao longo do dia, vindo a exibir mínimas de $103,77 \mathrm{~mol}^{\mathrm{m}-2 \mathrm{~s}-1}$ e máximas de $2483 \mathrm{~mol}^{\mathrm{m}-2 \mathrm{~s}-1}$ entorno das 7:30 e 13:00 horas, respectivamente (Figura 3).

FIGURA 3. Relação entre a condutância estomática e a radiação fotossinteticamente ativa

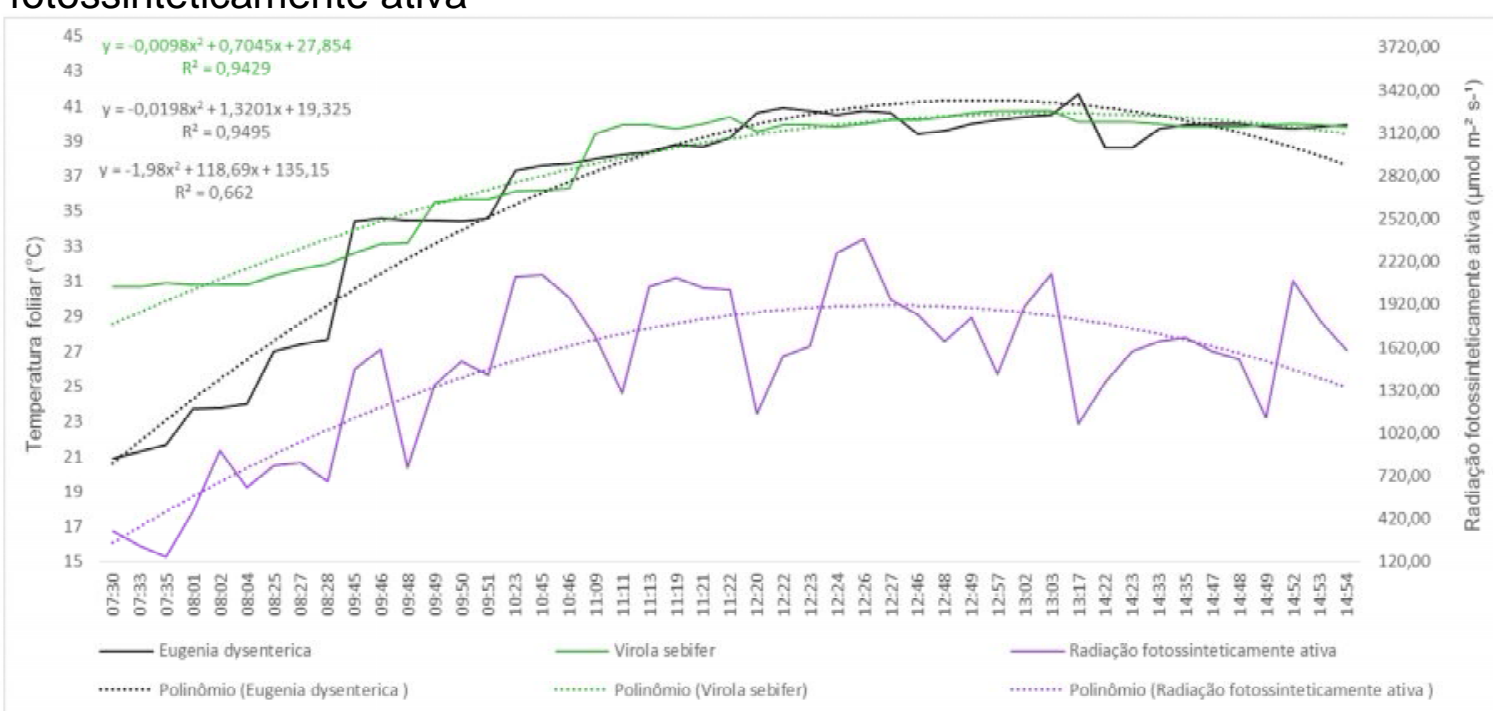

Fonte: Próprio autor. 
Foi observada relação direta entre a radiação fotossinteticamente ativa e a temperatura foliar de ambas espécies, contudo, essa relação foi mais forte para a Eugenia dysenterica $\left(r^{2}=0,81 ; p=0.00\right)$ que para Virola sebifer $\left(r^{2}=0,60 ; p=0.00\right)$ (Figura 4).

FIGURA 4. Efeito da temperatura foliar sobre a condutância estomática para as espécies Virola sebifer (painel A) e Eugenia dysenterica (painel B).

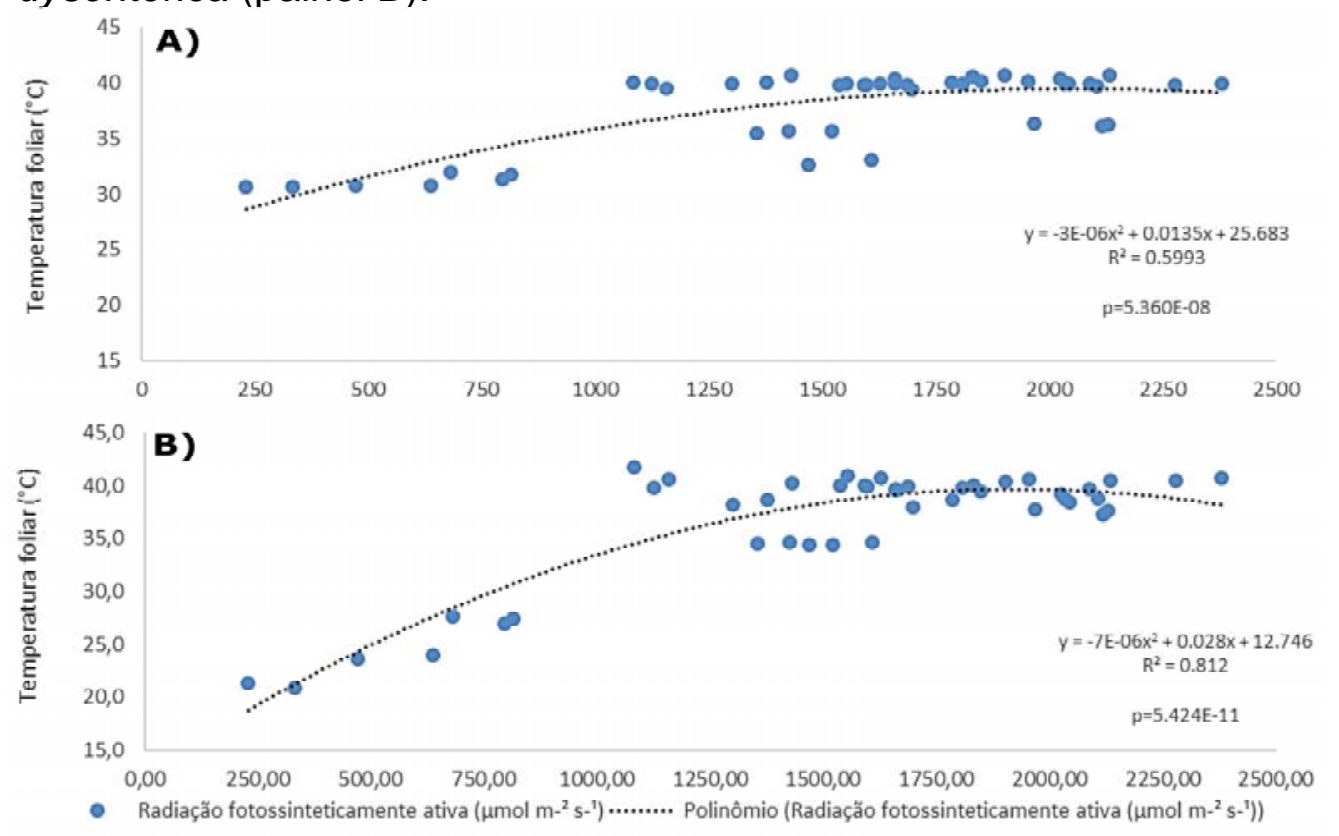

Fonte: Próprio autor.

Como um todo, os resultados evidenciados neste estudo indicaram que durante os dias mais quentes e secos de 2015 , o aumento exacerbado da radiação fotossintéticamente ativa juntamente com a elevada temperatura do ar, ocasionaram a elevação da temperatura foliar das espécies Eugenia dysenterica (média diária de $36,6^{\circ} \mathrm{C}$ ) e Virola sebifera (média diária de $33,8^{\circ} \mathrm{C}$ ), que por sua vez, fecharam os estômatos e reduziram a condutância estomática (MORAES; PRADO, 1998, KITAO et al., 2000). É preciso ressaltar ainda que, diversas estratégias podem estar envolvidas na tolerância ou adaptação das árvores a seca, e todos devem ser consideradas para avaliação de respostas vegetais ao estresse hídrico, nessa perspectiva, são sugeridos novos estudos para aferimentos mais definitivos.

\section{CONCLUSÕES}

As espécies Eugenia dysenterica e Virola sebifer apresentaram padrões de condutância estomática semelhantes, revelando que frente a um evento extremo de seca ambas as espécies tendem a aumentar a temperatura foliar e em consequência reduzir a condutância estomática.

De modo geral esses resultados revelam que as espécies da transição Cerrado-Amazônia são capazes de resistir a condições de elevado déficit hídrico. Ao mesmo tempo, é preciso ressaltar que ainda não se sabe por quanto tempo essas espécies podem resistir a essa condição de seca. Para tanto, sugere-se novos estudos que respondam essa nova pergunta aqui levantada, contribuindo AGRARIAN ACADEMY, Centro Científico Conhecer - Jandaia-GO, v.7, n.13; p. 92 2020 
assim com maiores informações a respeito de se conhecer os efeitos das mudanças climáticas na região de transição Cerrado-Amazônia.

\section{REFERÊNCIAS}

ALVARES, C.A.; STAPE, J.L.; SENTELHAS, P.C.; GONÇALVES, J.L. de M.; SPAROVEK, G. Köppen's climate classification map for Brazil. Meteorologische Zeitschrift, v.22, p .711 -728, 2013. Disponível em: < https://www.schweizerbart.de/papers/metz/detail/22/82078/Koppen_s_climate_clas sification_map_for_Brazil. 10.1127/0941-2948/2013/0507> Acesso em: 07 mar. 2019.

BERTOLLI, S. C.; SOUZA, J.; SOUZA, G. M. Caracterização fotossintética da espécie isohídrica pata-de-elefante em condições de deficiência hídrica. Revista Caatinga, v. 28, n. 3, p. 196-205, 2015. Disponível em: < https://www.scielo.br/scielo.php?pid=S1983-

21252015000300196\&script=sci_abstract\&tlng=pt. https://doi.org/10.1590/198321252015v28n322rc Acesso em: 10 mai. 2020.

BRAGA, E. O.; ROCHA, A. E. S.; NETO, S. V. C.; LIMA, T. T. S.; COSTA, L. G. S.; DE SOUZA MIRANDA, I. Biomassa e sazonalidade das raízes finas em savanas da Amazônia Oriental. Pesquisa Florestal Brasileira, v. 37, n. 92, p. 475-483, 2017. Disponível em: < https://pfb.cnpf.embrapa.br/pfb/index.php/pfb/article/view/1382. https://doi.org/10.4336/2017.pfb.37.92.1382> Acesso em: 11 mai. 2020.

CAIONI, C.; NEVES, S. M. A. S; CAIONI, S; BONINI, I.; PARENTE, T. L; SILVA, A. C. S. Dinâmica da temperatura superficial da microbacia Pedra do Índio durante a seca de 2013. Revista Espacios, v. 38, n 38, p.09-20, 2017. Disponível em: < https://www.revistaespacios.com/a17v38n38/a17v38n38p09.pdf> Acesso em: 15 jun. 2020.

CAIONI, C.; SILVÉRIO, D. V.; MACEDO, M. N.; COE, M. T.; BRANDO, P. M. Droughts Amplify Differences Between the Energy Balance Components of Amazon Forests and Croplands. Remote Sensing, v. 12, n. 3, p. 525, 2020. Disponível em: < https://www.mdpi.com/2072-4292/12/3/525. 10.3390/rs12030525> Acesso em: 15 jun. 2020.

CAMPOS, T. L. D. O. B.; DOS SANTOS, A. P. P. Frequências dos eventos extremos de seca e chuva na Amazônia utilizando diferentes bancos de dados de precipitação. Revista Brasileira de Geografia Física, v. 10, n. 2, p. 468-478, 2017. Disponível em: < https://periodicos.ufpe.br/revistas/rbgfe/article/view/234033. https://doi.org/10.5935/1984-2295.20170029> Acesso em: 16 jun. 2020.

CARNEIRO, K. M. S.; REIS, S. M.; MORANDI, P. S.; ELIAS, F.; OLIVEIRA, E. A. D.; MARIMON-JUNIOR, B. H.; ARIMON, B. S. Estoque e perda de necromassa da vegetação lenhosa em um gradiente fitofisionômico na transição AmazôniaCerrado. Rodriguésia, v. 70, 2019. Disponível em: < https://www.scielo.br/scielo.php?pid=S2175-

78602019000100258\&script=sci_abstract\&tlng=pt. http://dx.doi.org/10.1590/2175$7860201970060>$ Acesso em: $1 \overline{7}$ jan. 2020. 
CASAVECCHIA, B. H.; DE SOUZA, A. P.; STANGERLIN, D. M.; ULIANA, E. M.; MELO, R. R. Índices de perigo de incêndios em uma área de transição CerradoAmazônia. Revista de Ciências Agrárias, v. 42, n. 3, p. 842-854, 2019. Disponível em: $\quad<\quad$ https://revistas.rcaap.pt/rca/article/view/17756. https://doi.org/10.19084/rca.17756 > Acesso em: 16 jan. 2020.

COPERTINO, M. PIEDADE, M. T. F.; VIEIRA, I. C. G.; BUSTAMANTE, M. Desmatamento, fogo e clima estão intimamente conectados na Amazônia. Cienc. Cult., v. $\quad 71$, n. $\quad 4$, p. $\quad 04-05,2019 . \quad$ Disponível em: < http://cienciaecultura.bvs.br/pdf/cic/v71n4/v71n4a02.pdf> Acesso em: 17 jan. 2020.

CURTO, R.; WINK, C. ARAÚJO, E.; KOHLER, S. V. Modelos de relação hipsométrica por classe de aproveitamento em floresta de transição CerradoAmazônia no Mato Grosso. Enciclopédia biosfera, Goiânia, v. 10, n. 18, p. 687700, 2018. Disponível em: < http://www.conhecer.org.br/enciclop/2018B/AGRAR/modelos\%20de\%20relacao.pdf .10.18677/EnciBio_2018B60> Acesso em: 17 jan. 2020.

FURQUIM, L. C.; DOS SANTOS, M. P.; DE ANDRADE, C. A. O.; DE OLIVEIRA, L. A.; EVANGELISTA, A. W. P. Relação entre plantas nativas do Cerrado e água.Científic@-Multidisciplinary Journal, v. 5, n. 2, p. 146-156, 2018. Disponível em:

http://periodicos.unievangelica.edu.br/index.php/cientifica/article/view/2553.

https://doi.org/10.29247/2358-260X.2018v5i2.p146-156> Acesso em: 17 jan. 2020.

JANUARIO, I. R.; MOURA, M. A. L.; SANTOS, M. F.; VASCONCELOS, F. L.; BARROS, R. F. Análise intrasazonal da radição solar global (RG) e albedo em um ecossistema de mata atlântica. Revista Ibero-Americana de Ciências Ambientais, v.8, n.4, p.66-73, 2017. Disponível em: < https://sustenere.co/index.php/rica/article/view/SPC2179-6858.2017.004.0006. > Acesso em: 20 fev. 2020.

KITAO, M.; LEI, T. T.; KOIKE, T.; TOBITA, H.; MARUYAMA, Y.; MATSUMOTO, Y.; ANG, L. H. Temperature response and photoinhibition investigated by chlorophyll fluorescence measurements for four distinct species of dipterocarp trees. Physiologia Plantarum, v.109, p. 284-290, 2000. Disponível em: < https://onlinelibrary.wiley.com/doi/full/10.1034/j.1399-

3054.2000.100309.x?casa_token=OaZYZOboc1EAAAAA\%3A2hA6V4jtfSTevPTla3 uzv_Zewe3Zz3ZRHQZrT_6VDPxcbQQmg3GzszKMI-

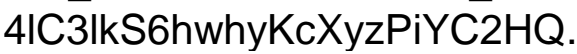

3054.2000.100309.x> Acesso em: 30 nov. 2019.

https://doi.org/10.1034/j.1399-

MARENGO, J. A.; WILLIAMS, E. R.; ALVES, L. M.; SOARES, W. R.; RODRIGUEZ, D. A. Extreme seasonal climate variations in the Amazon basin: droughts and floods. Springer, Berlin, Heidelberg, 2016. Disponível em: < https://link.springer.com/chapter/10.1007/978-3-662-49902-3_4.

https://doi.org/10.1007/978-3-662-49902-3_4> Acesso em: 03 nov. 2019. 
MORAES, J. A. P. V.; PRADO, C. H. B. Photosynthesis and water relations in cerrado vegetation. Oecologia Brasiliensis, v. 4, n. 1, p. 3, 1998. Disponível em: < https://www.researchgate.net/profile/Chba_Prado/publication/41003047_Photosynt hesis_And_Water_Relations_In_Cerrado_vegetation/links/0046352ea4ed88365300 0000/Photosynthesis-And-Water-Relations-In-Cerrado-vegetation.pdf.

10.4257/oeco.1998.0401.03> Acesso em: 20/fev. 2020.

MORAIS, V. A.; SANTOS, C. A.; MELLO, J. M.; DADID, H. C.; ARAÚJO, E. J. G.; SCOLFORO, J. R. S. Spatial and vertical distribution of litter and belowground carbon in a Brazilian Cerrado vegetation. Cerne, v. 23, n. 1, p. 43-52, 2017. Disponível em: <https://www.scielo.br/scielo.php?script=sci_arttext\&pid=S010477602017000100043. https://doi.org/10.1590/01047760201723012247 > Acesso em: 03 nov. 2019.

NOBRE, C. A.; SAMPAIO, G.; BORMA, L.; CASTILLA-RUBIO, J. C.; SILVA, J. S.; CARDOSO, M. Fate of the Amazon forests and the Third Way. Proceedings of the National Academy of Sciences, v. 113, n. 39, p. 10759-10768, 2016. Disponível em: <> Acesso em: 14/dez. 2019.

NOVAIS, J. W. Z.; SANCHES, L.; DE MORAES DIAS, V. R.; MACHADO, N. G.; DA SILVA, L. B.; AQUINO, A. M. Variação espaço-temporal da PAR refletida pelo solo e transmitida pelo dossel em floresta inundável no Pantanal matogrossense. Ciência Florestal, v. 28, n. 4, p. 1502-1513, 2018. Disponível em: < https://www.scielo.br/scielo.php?pid=S1980-

50982018000401502\&script=sci_arttext. https://doi.org/10.5902/1980509835097> Acesso em: 20 fev. 2020.

OREN, R.; SPERRY, J.S.; KATUL, G.G.; PATAKI, D.E.; EWERS, B.E.; PHILLIPS, N.; SCHAFER, K.V.R. Survey and synthesis of intra- and interspecific variation in stomatal sensitivity to vapour pressure deficit. Plant, Cell and Environment, v.22, p. 1515-1526, 1999. Disponível em: < https://onlinelibrary.wiley.com/doi/10.1046/j.1365-3040.1999.00513.x.

https://doi.org/10.1046/j.1365-3040.1999.00513.x> Acesso em: 14 dez. 2019.

REIS, G. P.; OLIVEIRA MORAES, E. Variação da umidade relativa do ar no coração da floresta Amazônica, um estudo de caso no município de Coari (AM) durante o ano de 2015. Os Desafios da Geografia Física na Fronteira do Conhecimento, v. 1, p. 2479-2486, 2017. Disponível em: <https://ocs.ige.unicamp.br/ojs/sbgfa/article/view/2048.https://doi.org/10.20396/sbgf a.v1i2017.2048> Acesso em: 14 dez. 2019.

RODRIGUES. W. P.; SILVA J. R.; FERREIRA L. S.; FERRAZ, T. M.; CAMPOSTRINI, E. Stomatal and photochemical limitations of photosynthesis in coffee (Coffea spp.) plants subjected to elevated temperatures. Crop and Pasture

Science, v. 69 , n.3, p. 317-325, 2018. Disponível em: <https://bioone.org/journals/Crop-and-Pasture-Science/volume-69/issue3/CP17044/Stomatal-and-photochemical-limitations-of-photosynthesis-in-coffeeCoffea-spp/10.1071/CP17044.short?tab=ArticleLinkSupplemental. 10.1071/CP17044> Acesso em: 20 fev. 2020. 
ROTHMUND, L. D.; ALMEIRA JR, E. S.; DE ARRUDA LIMA, L. P.; MASSAD, H. A. B.; SILVA PALÁCIOS, R.; BIUDES, M. S.; SOUZA NOGUEIRA, J. Impacto da alteração da cobertura do solo nos parâmetros biofísicos no sul da floresta amazônica por sensoriamento remoto. Revista Brasileira de Climatologia, v. 25, 2019. Disponível em: <https://revistas.ufpr.br/revistaabclima/article/view/62677. http://dx.doi.org/10.5380/abclima.v25i0.62677> Acesso em: 18/jan. 2020.

SANTOS, T. O. Os impactos do desmatamento e queimadas de origem antrópica sobre o clima da Amazônia brasileira: um estudo de revisão. Revista Geográfica Acadêmica, v.11, n.2, p.157-181, 2017. Disponível em: < https://revista.ufrr.br/rga/article/view/4430 > Acesso em: 20/fev. 2020.

SANTOS GOMES, A. C.; COSTA, G. B.; DA SILVA, J. T.; COUTINHO, M. D. L.; DA SILVA COSTA, M.; FITZJARRALD, D. R. Seca e a saúde das populações residentes em regiões da Amazônia brasileira nos anos de 2005, 2010 e 2015. Revista Brasileira de Climatologia, v. 23, p. 289-306, 2018. Disponível em: $<$

https://revistas.ufpr.br/revistaabclima/article/view/50256. http://dx.doi.org/10.5380/a bclima.v23i0.50256> Acesso em: 14 dez. 2019.

SILVA, M. R.; JARDIM, C. H. Influência da Topografia e Uso da Terra na Variação dos Elementos Climáticos em Belo Horizonte, Ibirité, Sete Lagoas e Conceição do Mato Dentro-MG: O Segmento Temporal Entre 11 a 23/09/2016. Revista do Departamento de Geografia, p. 48-57, 2017. Disponível em: < http://www.revistas.usp.br/rdg/article/view/132753.

https://doi.org/10.11606/rdg.v0ispe.132753> Acesso em: 20 fev. 2020.

SCHOLANDER, P. F., HAMMEL, H. T., BRADSTREET, E. D. \& HEMMINGEN, A. E. Sap pressure in vascular plants. Science, v.148, p. 339-346, 1965. Disponível em: < https://science.sciencemag.org/content/148/3668/339. 10.1126/science.148.3668.339> Acesso em: 14/dez. 2019.

SCHLESINGER, W. H.; DIETZE, M. C.; JACKSON, R. B.; PHILLIPS, R. P.; RHOADES, C. C.; RUSTAD, L. E.; VOSE, J. M. Forest biogeochemistry in response to drought. Global Change Biology, v.22, n.7, p. 2318-2328, 2016. Disponível em: <https://onlinelibrary.wiley.com/doi/abs/10.1111/gcb.13105. doi.org/10.1111/gcb.13105> Acesso em: 14 dez. 2019. 